\title{
Exploring the RNA landscape of endothelial exosomes
}

\author{
JENNIFER PÉREZ-BOZA, MICHELLE LION, and INGRID STRUMAN \\ Laboratory of Molecular Angiogenesis, GIGA-R, University of Liège, 4000 Liège, Belgium
}

\begin{abstract}
Exosomes are small extracellular vesicles of around $100 \mathrm{~nm}$ of diameter produced by most cell types. These vesicles carry nucleic acids, proteins, lipids, and other biomolecules and function as carriers of biological information in processes of extracellular communication. The content of exosomes is regulated by the external and internal microenvironment of the parent cell, but the intrinsic mechanisms of loading of molecules into exosomes are still not completely elucidated. In this study, by the use of next-generation sequencing we have characterized in depth the RNA composition of healthy endothelial cells and exosomes and provided an accurate profile of the different coding and noncoding RNA species found per compartment. We have also discovered a set of unique genes preferentially included (or excluded) into vesicles. Moreover, after studying the enrichment of RNA motifs in the genes unequally distributed between cells and exosomes, we have detected a set of enriched sequences for several classes of RNA. In conclusion, our results provide the basis for studying the involvement of RNA-binding proteins capable of recognizing RNA sequences and their role in the export of RNAs into exosomes.
\end{abstract}

Keywords: exosomes; noncoding RNA; RNA export; extracellular vesicles

\section{INTRODUCTION}

Exosomes are small vesicles of $\sim 100 \mathrm{~nm}$ diameter produced by virtually all cell types. These vesicles are formed via the endocytic pathway (Friand et al. 2015) and are characterized by the presence of specific exosomal surface markers (Simons and Raposo 2009) and a subset of proteins linked to the producing cell type and cell state (Keerthikumar et al. 2016). Cells produce exosomes as a method of autocrine, endocrine, and paracrine communication (Mathivanan et al. 2010). These vesicles have been linked to many cellular processes ranging from viral infection (Yoon et al. 2016) to chemotherapeutic resistance (Ji et al. 2015), and they have become an important source of biomarkers for a wide range of diseases (Momen-Heravi et al. 2015; Øverbye et al. 2015; Solé et al. 2015; Zhou et al. 2015).

The content of exosomes has been widely characterized in the past few years. It has been described that exosomes contain a mixture of genetic material (DNA and RNA), proteins, and lipids (Skogberg et al. 2013). The composition of exosomes is modulated by the state and stimuli of the cells at the time of exosomal production. For example, the RNA content of exosomes is regulated by the microenvironment of the parent cells (Challagundla et al. 2015) and can indicate the fate of the cell or cellular system (Li et al. 2016). Several studies have proven that exosomes are carriers of coding (Lv et al. 2014; Peake et al. 2014) and noncoding RNAs (Umezu et al.

Corresponding author: i.struman@ulg.ac.be

Article is online at http://www.rnajournal.org/cgi/doi/10.1261/rna. 064352.117.
2014; Berrondo et al. 2016; Qu et al. 2016) used by the cells as an intercellular network of communication, and that the transmission of these RNA molecules can modify the phenotype of the recipient cells.

Even though the mechanisms underlying the loading of RNAs into exosomes are still mostly unknown, a few RNAbinding proteins have been found capable of selectively binding RNA molecules with specific motifs and inducing their export into exosomes (Villarroya-Beltri et al. 2013; Santangelo et al. 2016; Shurtleff et al. 2016; Kossinova et al. 2017). In this study, we have addressed the composition of coding and noncoding RNAs in cells and exosomes from human primary endothelial cells. By the combination of small RNA and total RNA sequencing, we have been able to characterize the coding and noncoding RNA content of exosomes and cells, thus providing an unbiased database of the RNA composition of healthy primary endothelial cells. Interestingly, we found that although the ratio of the diverse subclasses of RNA is very similar in cells and exosomes, for some of them the nature of the sequences is very different. Moreover, we identified a set of motifs for several RNA subclasses specifically enriched in cells or in exosomes, information that can be set as the basis to find a complete new set of RNA-binding proteins to help elucidate the mechanisms of exosomal RNA export.

C 2018 Pérez-Boza et al. This article is distributed exclusively by the RNA Society for the first 12 months after the full-issue publication date (see http:// rnajournal.cshlp.org/site/misc/terms.xhtml). After 12 months, it is available under a Creative Commons License (Attribution-NonCommercial 4.0 International), as described at http://creativecommons.org/licenses/by-nc/4.0/. 


\section{RESULTS}

\section{Purification and characterization of exosomes}

Exosomes were collected from the supernatant of HUVEC and purified by ultracentrifugation. The size distribution of exosomes was analyzed using dynamic light scattering (DLS). As shown in Supplemental Figure S1A, the size distribution of the vesicles ranges from 50 to $150 \mathrm{~nm}$ with the majority of the particles appearing around $100 \mathrm{~nm}$, the expected size of exosomes. The quality of exosomes was assessed at protein level following the recommendations presented by Lötvall et al. (2014). The proteins identified by western blotting were the tetraspanins CD9, CD63, and CD81; the cytosolic protein ANXA2, the mitochondrial protein cytochrome $\mathrm{C}$, and the cellular protein AGO2 (Supplemental Fig. S1B). As expected, the exosomal markers (tetraspanins) were enriched in the extracellular fraction, while the levels of cytosolic proteins were similar in both samples. Both cytochrome C and AGO2 were only present in the cellular lysate, thus proving that no contamination of cellular materials was copurified with exosomes. These results indicate that the purified fraction is mostly composed of exosomes devoid of cellular contamination. The RNA composition of cells and exosomes (Supplemental Fig. S1C,D) differs substantially: The cellular fraction is mostly composed of the two rRNA major complexes $18 \mathrm{~S}$ and $28 \mathrm{~S}$, while exosomal RNA is mostly composed of short sequences.

\section{Exosomes are enriched in small RNA fragments}

To explore the RNA profile of the HUVEC and exosomes, we carried out the RNA-seq profile analysis for both small and long RNA. The main difference between long and small RNA sequencing is that in the first case, the library preparation procedure includes a step of size selection of small RNA fragments by electrophoresis, selecting only fragments from 16 to 40 nucleotides (nt). The quality of the sequencing was assessed using FastQC after demultiplexing and trimming the samples. Only good quality samples were used for further analysis. We noticed important differences after the trimming (and discarding samples shorter than $16 \mathrm{nt}$ ) of cellular and exosomal samples (Table 1). The proportion of reads lost after trimming the exosomal samples was much greater than the cellular samples, on average $62 \%$ vs. $18 \%$, respectively. These results are in agreement with previously published data, suggesting that most of exosomal RNA is small fragmented RNA (Jenjaroenpun et al. 2013). Then small and long RNA libraries were mapped to coding or noncoding genomes (the strategy followed is detailed in Fig. 1) and the heterogeneity of the samples after mapping and annotating them to the full human genome (version GRCh38) was assessed in a principal component analysis, Supplemental Figure S2.

\section{The distribution of RNA subclasses differs between cells and exosomes}

In order to determine if the diversity of small RNA fragments followed a random distribution in exosomes, we decided to study the abundance of mapped reads in each library per fragment size. The majority of small RNAs from the cellular libraries were distributed in two peaks corresponding to the expected size of microRNAs (22-23 nt) and then a secondary and weaker peak was observed for piRNAs (28-31 nt) (Fig. 2A). In contrast, in exosomal samples (Fig. 2B), these two populations were not overrepresented.

Next we assessed the distribution of coding and noncoding RNA classes in RNA fragments ranging from 16 to $40 \mathrm{nt}$. The study of the distribution of RNA species along small RNA fragments shows that even though there was an accumulation of small fragments in exosomes, the relative abundance of microRNAs in the extracellular vesicles is actually smaller than in cells ( $\sim 37 \%$ and $\sim 2 \%$, respectively), even though the distribution seems to follow the same size pattern in both compartments. yRNAs were present in both samples with sequences mapping to the expected size for mature yRNAs only (from 30 to $34 \mathrm{nt}$ ). The detection of snoRNAs and snRNAs in small libraries (detecting only RNAs ranging from 16 to $40 \mathrm{nt}$ ) indicates the presence of processed fragments of these RNA classes. Moreover, snoRNA fragments with a size from 25 to $40 \mathrm{nt}$ seem to be exclusively present in cells, while snRNA fragments are overrepresented in exosomes. Of note, a peculiar feature observed in exosomes is the high number of reads attributed to long coding and noncoding RNAs with very short sequence size (below $20 \mathrm{nt}$ ) (Fig. 2C,D).

TABLE 1. Summary of number of reads before and after trimming the samples

\begin{tabular}{llll}
\hline & \multicolumn{1}{c}{ Small RNA } & Relative reads lost \\
\cline { 2 - 4 } & \multicolumn{1}{c}{ Cells R1 } & \multicolumn{1}{c}{ Cells R2 } & $18.17 \%$ \\
\hline Before trimming & $28,487,715$ & $32,863,198$ & \\
After trimming & $24,680,059$ & $25,314,942$ & Relative reads lost \\
& Exosomes R1 & Exosomes R2 & $62.16 \%$ \\
Before trimming & $26,619,863$ & $31,692,435$ & $12,059,856$ \\
After trimming & $10,015,717$ & 12,056 & \\
\hline
\end{tabular}

Adaptor sequences were trimmed from the samples using Trimmomatic, and sequences shorter than 16 nt post-trimming were discarded. 


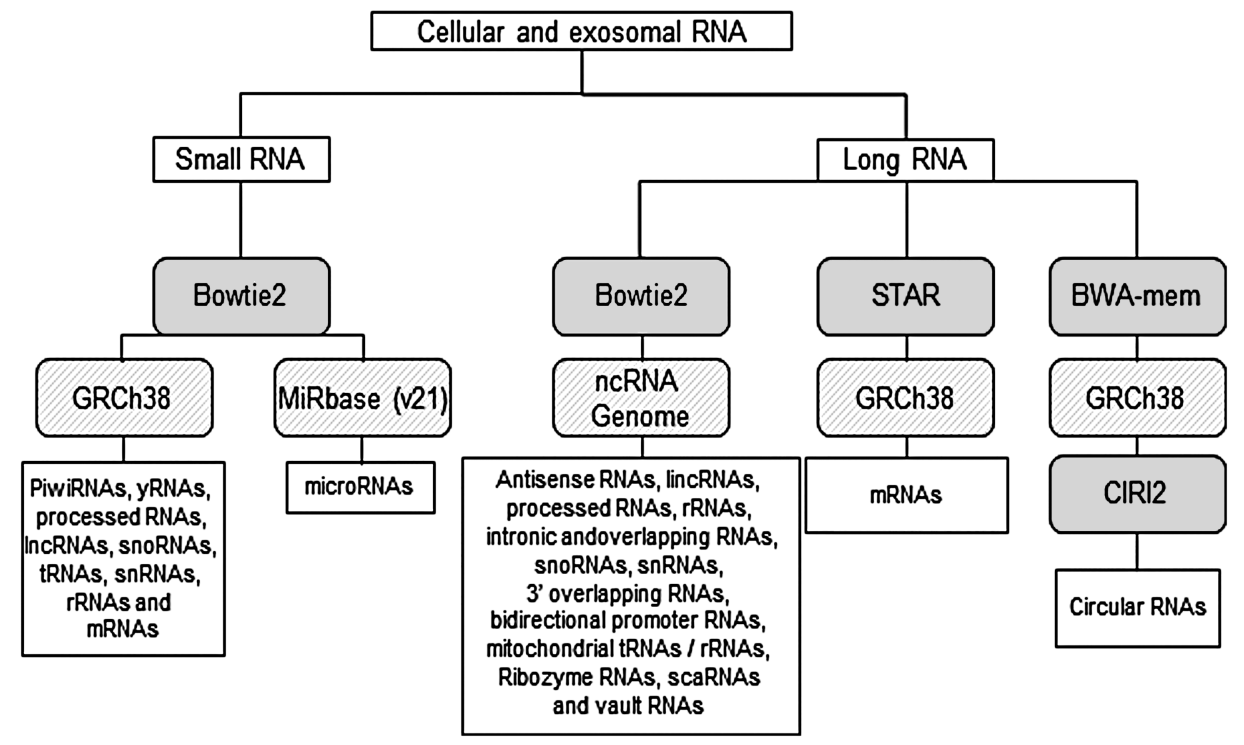

FIGURE 1. Flowchart of RNA-seq analysis. RNA from both cellular and exosomal origin was sequenced separately for small and long RNA analysis. The bioinformatic tools used for mapping (in gray) of the libraries were Bowtie2 for noncoding RNA and microRNAs, BWA-mem and CIRI2 for circular RNA, and STAR for coding RNA. The databases used to map the reads are underlined in gray lined boxes and are as follows: full human coding genome (version GRCh38), miRBase (v21), and ncRNA genome (obtained from Ensembl under "noncoding genome"). The RNA classes detected with each strategy are the following: piwi-interacting RNAs (piwiRNAs), yRNAs, processed transcript RNAs, long intergenic noncoding RNAs (lincRNAs), small nucleolar RNAs (snoRNAs), transfer RNAs (tRNAs), small nuclear RNAs (snRNAs), ribosomal RNAs (rRNAs), messenger RNAs (mRNAs), microRNAs, antisense RNAs, sense intronic RNAs, sense overlapping RNAs, 3'-overlapping RNAs, bidirectional promoter RNAs, mitochondrial transfer RNAs (Mt tRNAs), mitochondrial ribosomal RNAs (Mt rRNAs), ribozyme RNAs, small Cajal bodies RNAs (ScaRNAs), vaultRNAs, and circular RNAs.

For the analysis of long RNAs, sequences from the total RNA libraries were mapped against the coding (Aken et al. 2017) or the noncoding genome (Pignatelli et al. 2016). The noncoding genes were classified following the Ensembl guidelines into long noncoding RNAs (lncRNAs), short noncoding RNAs (ncRNAs), or processed transcripts (genes without an open reading frame that cannot be included in any of the two previous groups). In the first group (lncRNAs), a second subclassification was performed and genes were separated into 3'-overlapping ncRNAs, antisenseRNA, lincRNA, sense intronic, and sense overlapping RNAs. In the case of small ncRNAs, the genes were classified into microRNAs, piRNAs, rRNAs, snRNAs, snoRNAs, yRNAs, tRNAs, scaRNAs, and vault RNAs. A more detailed definition of these subclasses can be found in Supplemental Table S1.

While only the best alignment was reported for the mapping against the coding genome, multiple matching was allowed for the noncoding RNAs. This method resulted in single reads mapping to several isoforms within the same gene family (with high sequence homology). This, combined with the gene redundancy of ncRNAs (some small ncRNAs fall within the coordinates of longer ncRNAs), resulted in a greater number of reads per gene type. The results in Figure 3A show the mean levels and standard deviation of each one of the RNA subclasses normalized per library size $\left(10^{6}\right)$. The vast majority of identified genes fell within four major groups: lincRNAs, antisense RNAs, processed transcript RNAs, and mRNAs in both compartments, followed by microRNAs in cells and sense intronic RNAs in exosomes. On the opposite, the less-expressed RNA subclasses in cells were vault RNAs and circularRNAs. Because the detection of circular RNAs is based on the joint detection of spliced sequences from distant locations in the genome, we considered that the low mapping levels of this RNA class was an artifact created by the sequencing length $(75 \mathrm{bp})$ : The length of the reads after finding the splicing point was not enough to properly map the genome in the cases where the splicing point was too close to the ends of the read.

In order to analyze if the distribution of RNA classes is similar in long and short sequences, we assessed the level of each RNA class in cells and exosomes. We observed that even though more mRNA sequences were detected in the small RNA libraries (Fig. 3B), when the total RNA is sequenced (Fig. 3C), the main difference is the proportion of mRNA in exosomes. These results indicate that most of the exosomal RNA mapping to coding sequences is identified in very short sequences (up to $40 \mathrm{nt}$ ).

In conclusion, most of the RNA subclasses are equally represented in both compartments except for mRNAs and microRNAs that are more present in cells.

\section{Some, but not all, RNA subclasses are differentially distributed in cells and exosomes}

In order to determine if some specific RNAs were selectively exported into exosomes or retained in cells, we analyzed the 

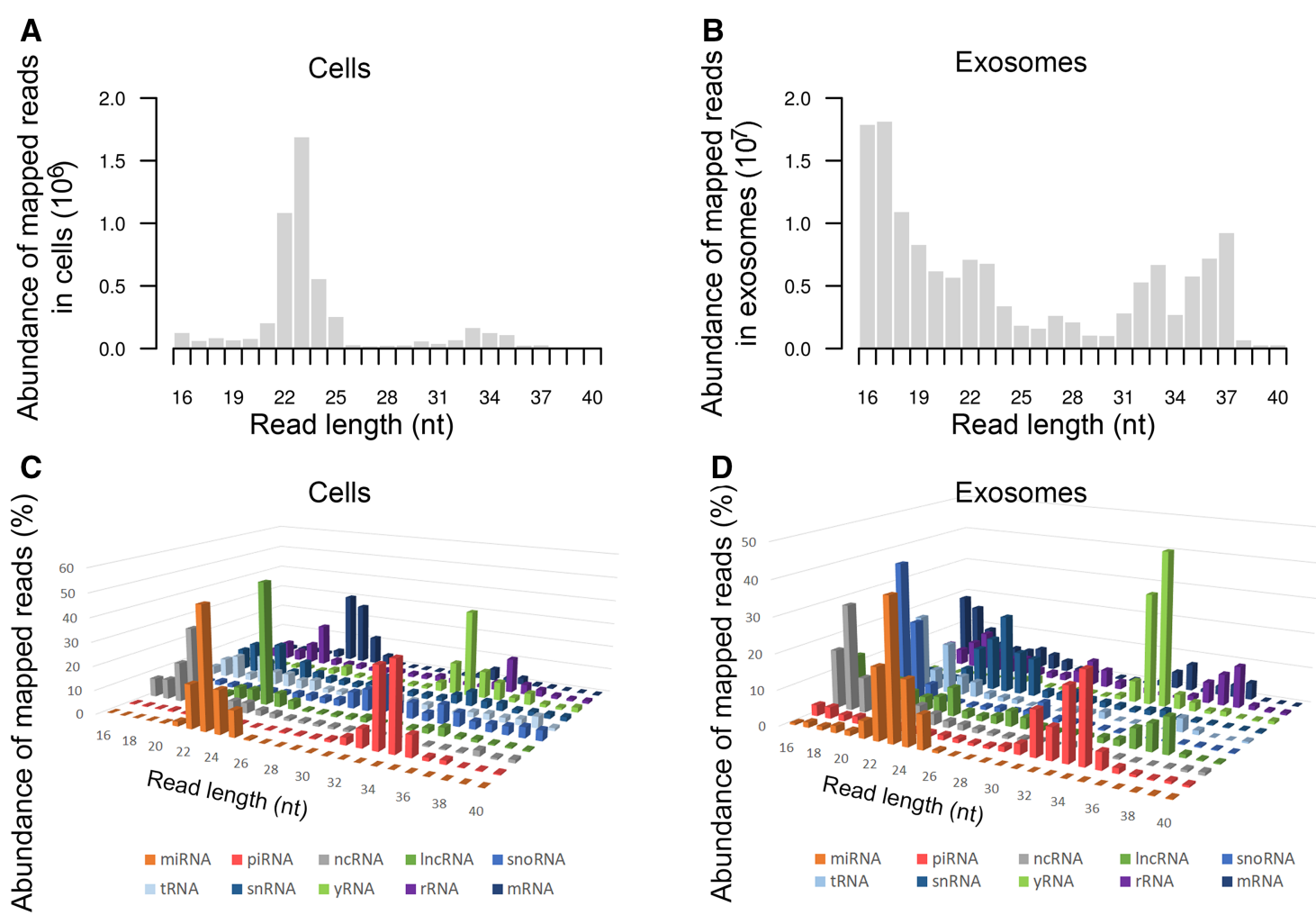

FIGURE 2. Small RNA profiles of HUVEC cells and exosomes. Top panels show the abundance of the sequences post-trimming along the length of size-selected reads (16-40 nt) obtained by sequencing of small RNA libraries for cells $(A)$ and exosomes $(B)$. Bottom panels (cells [C] and exosomes $[D])$ show length distribution plotted against abundance of the reads annotated for the indicated RNA subclasses after normalization per RNA type.

distribution of each individual RNA in the RNA subclasses described above. To do so, the identified RNA genes were segregated by RNA subclass and then by cellular compartment into three subcategories: only present in cells, only present in exosomes, and present in both compartments. Figure $4 \mathrm{~A}$ shows the number of genes for which the RNA was found uniquely in one of the other compartments or in both. In order to evaluate if the distribution is different among the different RNA subclasses, data are also shown as percentage of different genes found per compartment normalized by the total number of genes known within each RNA subtype (Fig. 4B).

For all the RNA species studied, the majority of different RNA molecules were found in common in cells and in exosomes. Nevertheless, for mRNAs and bidirectional promoter lncRNAs, the number of genes uniquely identified in exosomes was greater than that uniquely found in cells. Strikingly, there were 2009 mRNA coding genes identified only in exosomes $(\sim 10 \%)$, while only $83(0.4 \%)$ were cell-specific (Fig. 4B). On the opposite, the diversity of microRNAs, snoRNAs, and scaRNAs was greater in cells. Together with the results shown in Figure 3, we can conclude that even though there are more mRNAs in cells than in exosomes, more unique mRNA genes are found in the vesicles.

Regarding small noncoding RNAs, of the 1375 miRNAs expressed in cells and exosomes, about $20 \%$ are exclusively detected in cells (360 miRNA), while only 11 are present only in exosomes $(0.4 \%)$. Of the 4169 piRNAs detected in total, 298 were exclusively found in cells $(1.4 \%)$, while 81 were detected uniquely in exosomes (0.4\%) (Fig. 4B). Except for mRNA, miRNA and piRNA, most of the RNAs subtypes are equally distributed between cells and exosomes.

\section{Distinctive regions of mRNA genes are exported in different proportions}

Because the subclass of RNA that is mostly present as small RNA in exosomes appeared to be mRNA, we decided to explore whether some regions of the coding gene were preferentially exported or retained in the cell. For that purpose, we separated the regions in the gene by $5^{\prime}$-UTR, coding sequence (CDS), and $3^{\prime}$ UTR. Our study revealed that the distribution of the RNA regions studied (5'UTR, CDS, and 3'UTR) was present in different proportions in cells and in exosomes. Figure 5 shows the ratio of reads per region in exosomes vs. cells. This analysis was performed only for the genes in which reads were detected in all three regions; this represents a total of 2223 genes that were classified into 50 clusters. Genes can be separated into four different groups with similar ratios per region: In the first group (730 genes), all regions of the genes are more abundant in exosomes than in cells, but the ratio of $3^{\prime}$ UTRs is higher than for the other regions. In the second 
A

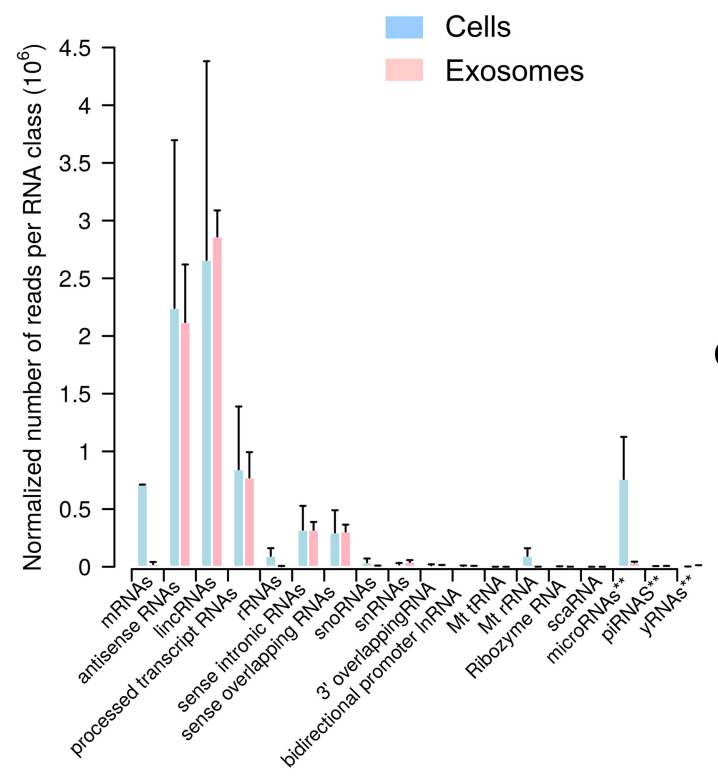

B

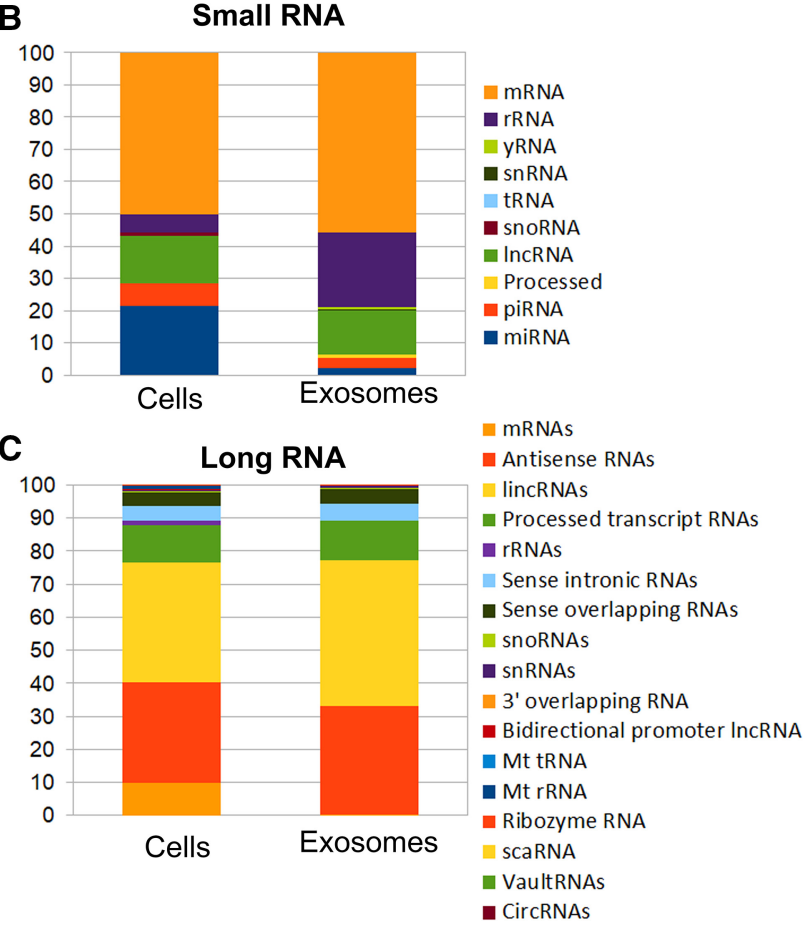

FIGURE 3. RNA profiles of HUVEC cells and exosomes. (A) The RNA molecules detected in cells or in exosomes were segregated by RNA class and normalized by library size $\left(10^{6}\right)$. MicroRNAs, piRNAs, and yRNAs $\left({ }^{* *}\right)$ were counted and normalized by the size of the small RNA libraries, and the remaining categories were identified and normalized using the total number of reads of long RNA libraries. $(B, C)$ Distribution of the RNA species in HUVEC and Exosome. For both small $(B)$ and total $(C)$ RNA libraries, the identified genes were classified per RNA class and normalized by total number of genes detected for both cellular and exosomal libraries. Short RNA classes (yRNAs, miRNAs, and piRNAs) were only considered in the small RNA libraries; and circular RNAs, Vault RNAs, scaRNAs, Ribozyme RNAs, mitochondrial tRNA, and rRNA, bidirectional promoter lncRNA, 3'overlapping RNA, sense intronic and overlapping RNA, processed transcript RNA, lincRNA, and antisense RNA were only segregated in total RNA libraries and combined into lncRNAs and processed RNAs in small RNA libraries.

group (343 genes), $3^{\prime}$ UTRs are also relatively more present in exosomes than in cells, although the other regions are more present in cells or in a very similar proportion. The third group (424 genes) is composed of clusters of genes that present more reads in cells than in exosomes for all regions, while the last and fourth group (726 genes) represent genes that are present in very similar proportions in both compartments. In conclusion, we found that all genes do not follow the same distribution. While the rate of export of some genes (groups 3 and 4) is similar for all the regions, the others (groups 1 and 2) show elevated levels of $3^{\prime}$ UTR in relation to the other regions in exosomes compared to cells.

\section{RNA motifs are specifically enriched in one cellular compartment for some, but not all, RNA subtypes}

We then wondered whether some RNA motifs could be involved in the export of RNA classes into exosomes. For that purpose, using HOMER we performed a motif enrichment analysis in the genes segregated per RNA class and subclassified into four different categories: only present in cells, only present in exosomes, present in both compartments but significantly more present in cells, and present in both compartments but significantly more present in exosomes. A list with all the genes found only in one compartment for each RNA class assessed and the ones significantly enriched $(P$ value after FDR correction $<0.05)$ in either cells or exosomes can be found in Supplemental Table S2.

The motif search analysis was able to find significantly enriched repetitive sequences for lincRNAs and processed transcript RNAs among all four segregated categories: the genes only found in one or the other compartment and in those significantly more present in cells or in exosomes. For antisense RNAs, common sequences were found in the genes present in only one of the compartments (both in cells or exosomes) and in those common to both subcellular compartments but significantly more present in exosomes. The most significantly enriched motifs per RNA subclass are summarized in Figure 6 and all the 180 significant enriched motifs are detailed in Supplemental Figure S3.

So far, only three proteins have been previously identified to be involved in specific export of RNA in exosomes. We thus decided to search for known motifs recognized by those three proteins, named hnRNPA2B1, SYNNCRIP, or YB1 (Fig. 7). We observed that the motif GGCUG, recognized by SYNCRIP, was found in one motif within those significant in antisense RNAs only found in exosomes. The motif recognized by hnRNPA2B1 was also found in antisense RNAs 
A

\begin{tabular}{|ccccc|}
\hline Class & Genome & Common & Cells & Exosomes \\
\hline mRNAs & 20310 & 14834 & 83 & 2009 \\
\hline Antisense RNAs & 11417 & 8968 & 728 & 251 \\
\hline LincRNAs & 14755 & 12174 & 341 & 564 \\
\hline Processed transcript RNAs & 3535 & 2176 & 224 & 113 \\
\hline rRNAs & 568 & 528 & 5 & 9 \\
\hline Sense intronic RNAs & 992 & 514 & 43 & 24 \\
\hline Sense overlapping RNAs & 350 & 315 & 10 & 12 \\
\hline snoRNAs & 1018 & 292 & 176 & 45 \\
\hline snRNAs & 2053 & 657 & 43 & 48 \\
\hline 3' Overlapping RNAs & 35 & 30 & 1 & 0 \\
\hline Bidirectional promoter IncRNAs & 24 & 14 & 1 & 3 \\
\hline Mt tRNA & 22 & 13 & 0 & 0 \\
\hline Mt rRNA & 2 & 2 & 0 & 0 \\
\hline scaRNAs & 52 & 2 & 4 & 0 \\
\hline tRNAs & 497 & 41 & 0 & 0 \\
\hline microRNAs & 2588 & 1004 & 360 & 11 \\
\hline piRNAs & 20869 & 3790 & 298 & 81 \\
\hline yRNAs & 4 & 4 & 0 & 0 \\
\hline
\end{tabular}

B

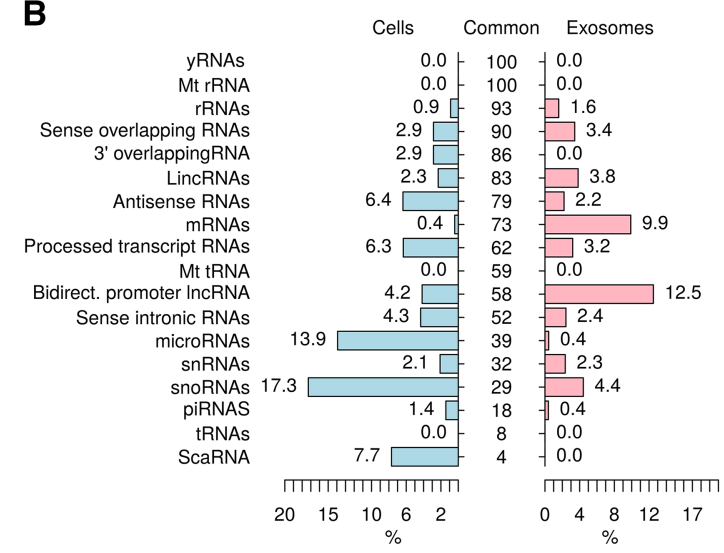

FIGURE 4. The diversity of RNAs in HUVEC and exosomes is differentially distributed in all RNA subclasses. (A) Data represent the number of unique and common RNA detected per compartment. The RNA molecules detected in cells or in exosomes were segregated by RNA class and the total number of unique genes was determined. Genome column represents the total number of genes known in that class. $(B)$ Data represent the percentage of detected RNA genes in each compartment normalized by the total number of genes known in that class.

enriched in exosomes, and finally in processed transcript RNAs only present in exosomes (in four independent larger motifs). Finally, the motif recognized by YB1 and NSUN2 was found in lincRNAs significantly more exported and one motif detected only by YB1 was partially found (except for the last $3^{\prime}$ nucleotide) in processed transcripts enriched in exosomes (present only in exosomes or significantly more present).

\section{DISCUSSION}

Several studies have described discrepancies in RNA content between cells and extracellular vesicles (Crescitelli et al. 2013; Jenjaroenpun et al. 2013; Miranda et al. 2014; LázaroIbáñez et al. 2017). In general lines, most studies have found an accumulation of small RNA fragments (Jenjaroenpun et al. 2013) and a high proportion of noncoding RNAs in the extracellular particles (Miranda et al. 2014; Quek et al. 2017). Our results suggest that instead of an accumulation of small RNA species in exosomes, these vesicles may be enriched in fragments of longer sequences. Moreover, in this study most, if not all, RNA species were detected both in cells and exosomes.

Even though the size distribution of RNAs in exosomes suggests an accumulation of short RNAs, the relative abundance of small RNAs (microRNAs, piwiRNAs, snRNAs, snoRNAs, and tRNAs) was much smaller than coding (mRNAs) or other longer noncoding RNAs. In general lines, the cellular RNA was mostly composed of lincRNAs and antisense RNAs followed by processed transcript RNA and messenger RNA. In exosomes, the two most common species were also lincRNAs and antisense RNAs, although the abundance of mRNAs was significantly reduced. It has been already shown that the distribution of long noncoding RNAs in exosomes is strongly related to the parent cell type (Chen et al. 2016) and that it can be regulated by disease and by changes in the cellular environment (Hewson et al.
2016; Lang et al. 2017; Pan et al. 2017). Exosomal lncRNAs have also been widely studied as biomarkers (Wang et al. 2014; Işin et al. 2015; Li et al. 2015; Liu et al. 2016) and it has been hypothesized that they may act as microRNA sponges to promote their export (Ahadi et al. 2016). Moreover, Gezer et al. (2014) proposed that lncRNAs with a low number of copies in the cells were more prone to be exported than others with a higher number of copies, which is in accordance with our results for lincRNAs: Even though the majority of genes were found in both compartments, the number of exclusively exosomal lincRNAs was slightly greater than that solely found in cells (564 vs. 341, respectively). Even though the presence of rRNA in exosomes is highly controversial (Mateescu et al. 2017), our results indicate that the amount of full-length rRNA is much lower in exosomes than in cells, results that are in agreement with the study published by Enderle et al. (2015). The levels of small rRNA fragments (16-40 nt) found in cells suggest that the accumulation of these fragments in exosomes is most likely a reflection of the RNA landscape in the cells. Although in the case of small RNA, the proportion of rRNA is greater, we hypothesized that this could be an artifact caused by the relative impoverishment of other RNA classes like microRNAs and piwiRNAs.

Regarding the presence of small RNAs, the most wellknown class of exosomal RNAs has been microRNAs. The study of these RNAs in exosomes conforms to the greatest group of publications in this type of vesicle to date. MicroRNAs have been described as biomarkers (for reviews, see Schwarzenbach 2015; Tsochandaridis et al. 2015; Joyce et al. 2016) and active players in intercellular communication (Hannafon and Ding 2013; Kosaka et al. 2013; Milane et al. 2015). Exosomal microRNAs are involved in a wide range of processes ranging from pre-metastatic niche preparation (Sánchez et al. 2016), chemotherapeutic resistance (Xu et al. 2017), or immunomodulation (Okoye et al. 2014). Even 


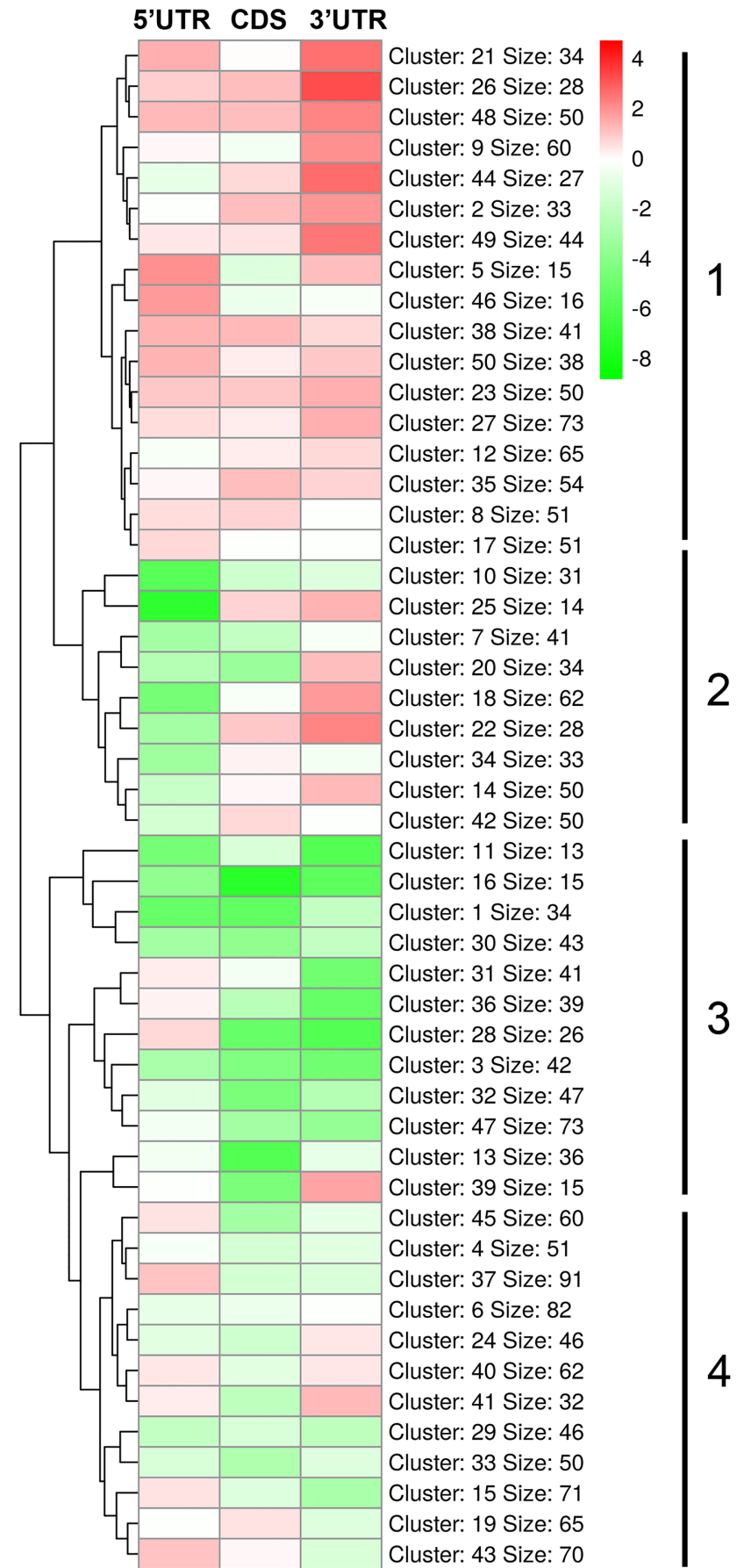

FIGURE 5. Regions of the genes are differentially exported into exosomes. For each gene found in common in cells and in exosomes with reads in the $5^{\prime}$ and $3^{\prime}$ UTR as well as in the coding sequence (CDS), the ratio of reads in exosomes vs. cells per region was assessed in each region. The heatmap shows the $\log _{2}$ of the fold change between exosomes and cells per region.

though the important role of this type of RNAs in exosomes has been widely proven, in our study we found that indeed, the abundance of microRNAs in exosomes when compared with other RNA classes is much smaller than in cells. Because not all microRNAs are present in exosomes and their export is often regulated in response to cellular stimuli, it is possible to hypothesize that the export of specific microRNAs under certain circumstances is an active process tightly regulated.

Of special interest in the past few years has been the type of noncoding yRNAs. These RNAs, initially discovered for their role in lupus (Lerner et al. 1981), were found later as stable partners of Ro ribonucleoprotein complexes. They are transcribed as small RNAs of 83-112, that after being processed into their mature form, range in size from 24$34 \mathrm{nt}$, and usually present a characteristic secondary stemloop structure (Farris et al. 1995). They have been found as biomarkers of coronary artery disease (Repetto et al. 2015) and they are involved in cardioprotection via IL-10 expression regulation (Cambier et al. 2017). Besides this, in the past couple of years, a few studies have detected circulating levels of these yRNA in serum and plasma (Fritz et al. 2016; Kaudewitz et al. 2016), and later on in extracellular vesicles such as exosomes (Chakrabortty et al. 2015; van Balkom et al. 2015; Cambier et al. 2017). In our samples, we were able to identify these RNAs in the small RNA libraries among the fragments ranging in sizes from 30 to $34 \mathrm{nt}$. Their concentration was not as high as other publications may have suggested before, likely indicating differences depending on the cellular type.

One very interesting observation highlighted by this work is the peculiar distribution of mRNA in cells and exosomes. Messenger RNAs have been earlier found in exosomes and some of them are suggested to be powerful biomarkers (Provencio et al. 2017; Xu et al. 2017). Other studies have shown that mRNAs are transported from the parent to the recipient cell via exosomes remaining active (Lobb et al. 2017). Here, we made the striking observation that even though most mRNA molecules were detected both in cells and in exosomes (14,834 different genes), the number of unique mRNA genes found in exosomes (2009) was much greater than that of the mRNAs exclusively found in cells (83 genes only). This observation suggests that some coding genes that are expressed in the cells are destined to the export and play a specific role in intercellular communication between other endothelial cells or with more distant recipient cells.

Some studies have previously suggested that specific regions of coding genes can be preferentially exported into exosomes. Batagov and Kurochkin (2013) showed, using data from a previous study in glioblastoma, that exosomal RNA was enriched in regions closer to the $3^{\prime}$ end, and that matches specifically to the $3^{\prime} \mathrm{UTR}$ regions. Our study has shown that in HUVEC exosomes, mRNA genes can be classified into three groups according to the origin of the reads mapping to coding sequences: $3^{\prime}$ UTRs enriched in exosomes, all regions more present in cells, and genes with similar ratios of expression in both compartments. Although for roughly half of the genes detected in both compartments, the reads were mostly originating from the $3^{\prime} \mathrm{UTR}$, we cannot conclude that there is a general mechanism promoting the export of all 


\begin{tabular}{|c|c|c|c|c|c|c|c|}
\hline Sequence Logo & Subgroup & Class & $\begin{array}{l}\text { Genes in } \\
\text { group }\end{array}$ & $\begin{array}{l}\text { Genes in } \\
\text { Background }\end{array}$ & $\begin{array}{l}\% \text { in } \\
\text { subgroup }\end{array}$ & $\begin{array}{l}\% \text { in } \\
\text { background }\end{array}$ & $p$-value \\
\hline & Cells Only & piwiRNAs & 298 & 4548 & 24.83 & 7.29 & $1 \cdot 10 \mathrm{e}-17$ \\
\hline & Cells Only & \multirow[t]{3}{*}{ Antisense RNA } & 728 & \multirow[t]{3}{*}{10926} & 4.40 & 0.74 & $1 \cdot 10 \mathrm{e}-12$ \\
\hline & Exosomes Only & & 215 & & 10.36 & 1.47 & $1 \cdot 10 \mathrm{e}-13$ \\
\hline & $\begin{array}{l}\text { Significantly more } \\
\text { present in exosomes }\end{array}$ & & 996 & & 54.49 & 37.74 & $1 \cdot 10 \mathrm{e}-23$ \\
\hline & Cells Only & \multirow[t]{4}{*}{ lincRNAs } & 341 & \multirow[t]{4}{*}{13984} & 9.09 & 1.09 & $1 \cdot 10 \mathrm{e}-17$ \\
\hline & Exosomes Only & & 564 & & 7.27 & 1.11 & $1 \cdot 10 \mathrm{e}-18$ \\
\hline & $\begin{array}{l}\text { Significantly more } \\
\text { present in Cells }\end{array}$ & & 1941 & & 20.61 & 8.65 & $1 \cdot 10 \mathrm{e}-48$ \\
\hline & $\begin{array}{l}\text { Significantly more } \\
\text { present in exosomes }\end{array}$ & & 1078 & & 10.25 & 2.15 & $1 \cdot 10 e-50$ \\
\hline & Cells Only & \multirow{4}{*}{$\begin{array}{l}\text { Processed } \\
\text { transcript } \\
\text { RNAs }\end{array}$} & 224 & \multirow[t]{4}{*}{3760} & 28.12 & 7.45 & $1 \cdot 10 \mathrm{e}-18$ \\
\hline & Exosomes Only & & 113 & & 23.01 & 1.43 & $1 \cdot 10 \mathrm{e}-20$ \\
\hline & $\begin{array}{l}\text { Significantly more } \\
\text { present in Cells }\end{array}$ & & 1125 & & 19.82 & 8.67 & $1 \cdot 10 \mathrm{e}-21$ \\
\hline & $\begin{array}{l}\text { Significantly more } \\
\text { present in exosomes }\end{array}$ & & 405 & & 17.78 & 4.40 & $1 \cdot 10 \mathrm{e}-19$ \\
\hline & Exosomes Only & mRNA & 2009 & 19018 & 5.72 & 2.19 & $1 \cdot 10 \mathrm{e}-16$ \\
\hline
\end{tabular}

FIGURE 6. Different motifs are enriched per compartment and are exclusive of each RNA subtype. The identified genes were classified by gene class and compartment localization. Then the full gene sequence was analyzed using HOMER to find common motifs when compared to a background database containing all the genes found in any or all cellular compartments per RNA class. This table shows, for each category in which we found significantly enriched motifs, the most overrepresented sequences per RNA class and compartment as well as the number of genes presenting this motif along with the estimated significance ( $P$-value). A full list of all motifs can be found in Supplemental Figure S3.

$3^{\prime}$ UTR fragments and the specificity in the export of these regions should be further assessed.

How RNAs are specifically exported into exosomes is currently an important challenge in the field of extracellular vesicles. Uneven distribution of small RNA species and fragments may suggest a possible mechanism by which only selective RNA fragments of specific size and type are exported into exosomes. To date, only three RNA-binding proteins have been identified as molecules involved in the export of small RNAs (microRNAs) into exosomes: hnRNPA2B1 (Villarroya-Beltri et al. 2013), SYNCRIP (or hnRNPQ) (Santangelo et al. 2016), and YB1 (Shurtleff et al. 2016). While the role in the export of microRNAs by hnRNPA2B1 and SYNCRIP seems to be based on motif recognition and selective binding followed by export, YB1 seems to be involved in the packaging of only two microRNAs, miR-223 and miR-144. Surprisingly, in our study, no motifs were found significantly enriched for microRNAs in any of the compartments, likely indicating different roles for these proteins depending on the cell type studied.

HnRNPA2B1 is a protein involved in the translocation of RNA molecules within the cell (Munro et al. 1999) and from viral particles (Lévesque et al. 2006). Also, members of the same family of RNPs are involved in the binding of mRNAs (Suzuki and Matsuoka 2017) and can regulate gene transcription (Zhang et al. 2017). SYNCRIP, another member of the hnRNP family, is a known splicing factor (Beuck et al. 2016), which is also involved in viral RNA replication (Choi et al. 2004; Liu et al. 2009) that also binds to mRNA (Kuchler et al. 2014) and that has an important role in mRNA transcription and degradation (Moser et al. 2007; Duning et al. 2008). Finally, YB1 is a protein involved in DNA repair and replication, and in RNA decay, stability, and transcription (Eliseeva et al. 2011; Lyabin et al. 2014). It has been mainly studied regarding its role in cancer progression and maintenance (Jung et al. 2014; Guo et al. 2017; Lim et al. 2017). Among other studies, two of special interest are the study published by Zhao et al. (2017) where they found that YB1 can interact with the IncRNA AWPPH in hepatocellular carcinoma cells promoting cellular growth; and the study by Wu et al. (2015), where they described that YB1 can regulate the expression and maturation of microRNAs via the binding of specific motifs. Moreover, a recent study proposed that YB1 can promote the export of all types of RNAs presenting any of three specific motifs depending on their polarity on the gene (Kossinova et al. 2017). 


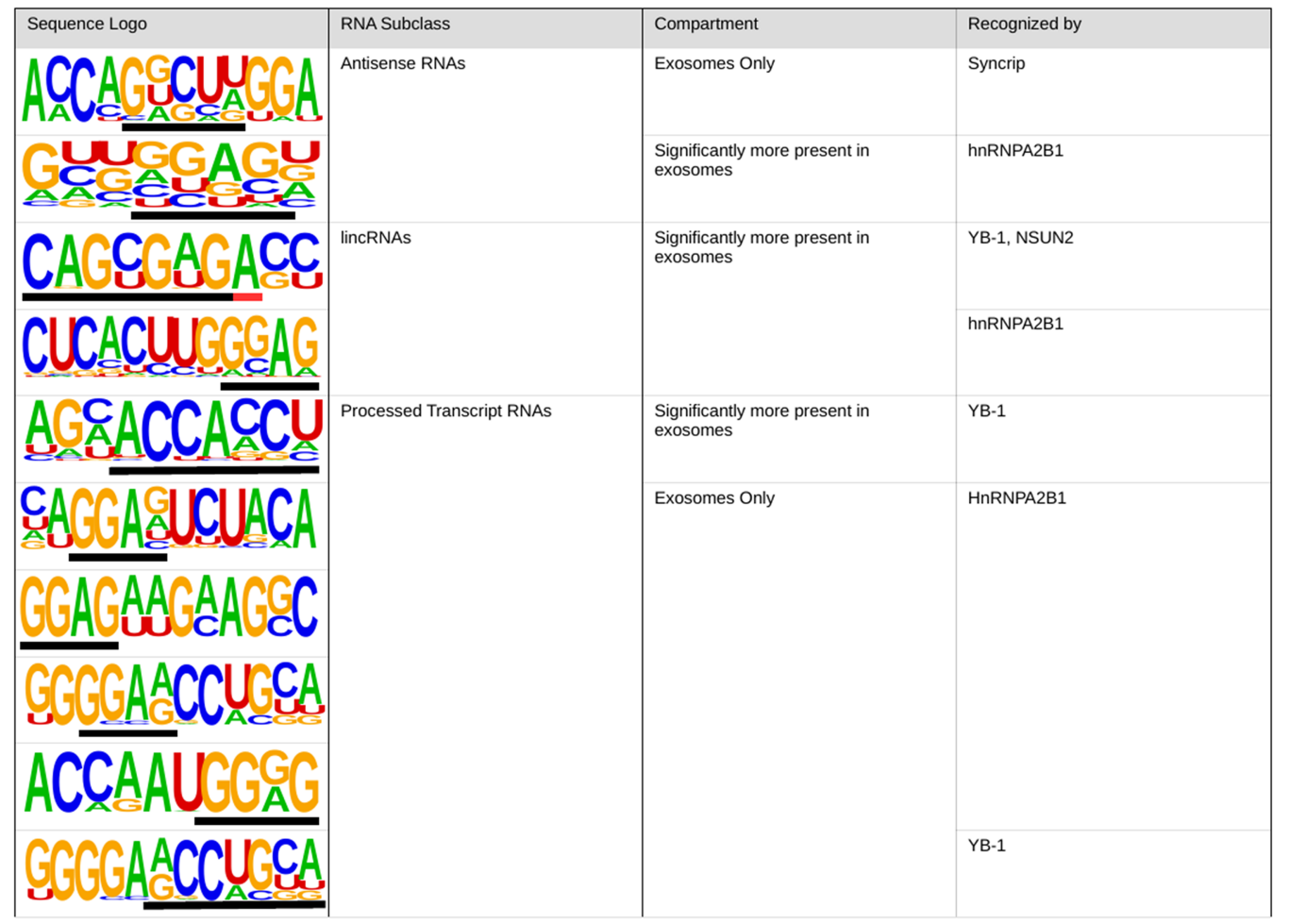

FIGURE 7. RNA motifs identified by RNA-binding proteins are found among the motifs detected in antisense RNAs, lincRNAs, and processed transcripts. All the sequences enriched in exosomes and found during the sequence enrichment analysis were compared to the motifs recognized by Syncrip (GGCUG), hnRNPA2B1 (GGAG and GGCUG), YB-1 (ACCAGCCU, CAGUGAGC, and UAAUCCCA), and NSUN2 (CAGUGAGC), involved in the export of RNA sequences to exosomes. The black lines underlying the motifs indicate the matching motifs and the red line indicates mismatches between the motifs found in this study and the ones recognized by the RNA-binding proteins involved in the export.

Because all these proteins are RNA-binding proteins not specific for microRNAs, it is logical to assume that the role that they have in RNA export into exosomes could also be extrapolated to other RNA subtypes. This theory gains value when we observe that of all the motifs described in the literature and found enriched in exosomes (GGAG, recognized by hnRNPA2B1, GGCUG recognized by hnRNPA2B1 and SYNCRIP, and ACCAGCCU, CAGUGAGC, and UAAUCCCA, all three recognized by YB1), several of them are present as part of the motifs enriched in our analysis. Since the sequence recognized by SYNCRIP that was found enriched in antisense noncoding RNAs is both significantly more present in exosomes and in those uniquely found in these vesicles, it is possible to hypothesize that this protein could be involved in the selective export of RNAs within this subclass. At the same time, the sequence recognized by hnRNPA2B1 was also enriched in both antisense RNAs, processed transcripts and lincRNAs that were present in both compartments but up-regulated in exosomes. Finally, our data suggest that the RNAs within the category "processed transcript RNA" were enriched in the motifs recognized by YB1. Even though it would be logical to expect to find the YB1 motifs enriched in mRNAs found in exosomes, we attribute the observed variation to differences in the cell type used. Our results suggest that other RNA-motif recognizing proteins might be involved in the exosomal export of some RNA subclasses based on the significant motifs found in this study.

In this study, we have characterized the RNA content of cellular and exosomal RNA on human endothelial cells in depth. Unlike many other profiling studies already published, we have used healthy primary cells to show the basal composition of RNA subclasses and to find the motifs significantly more present in cells or in exosomes basally. We have also proven that, even though microRNAs are by far the most studied class of RNAs in exosomes, they represent a very small amount of the total RNA content of these vesicles, thus setting the basis to promote a switch in exosomal RNA research toward longer RNAs.

\section{MATERIALS AND METHODS}

\section{Cellular cultures and exosome production}

HUVEC were isolated from umbilical veins. The veins were washed with PBS, filled with trypsin solution (0.05\% trypsin [Difco]; $0.2 \%$ EDTA; PBS; $\mathrm{pH} 7.6$ ), clamped, and incubated in a $37^{\circ} \mathrm{C}$ water bath for $20 \mathrm{~min}$. The umbilical vein was then washed with PBS and the eluate was centrifuged to harvest cells. HUVECs were cultured in Endothelial Cell Growth Media-2 (EGM2) (Lonza) supplemented 
with Supreme Serum (Lonza) 5\% (v/v) exosome depleted (exosomes were depleted from the serum by overnight centrifugation at $110,000 \mathrm{~g}$ and $4^{\circ} \mathrm{C}$ ). Cells were incubated at $37^{\circ} \mathrm{C}$ and $5 \% \mathrm{CO}_{2}$ up to passage 10 . For the exosome production, cells were seed in three T75 flasks in $10 \mathrm{~mL}$ of media so that $72 \mathrm{~h}$ later they would have reached $85 \%-90 \%$ confluence. The supernatant was then recovered and exosomes were purified by sequential ultracentrifugation: The media was first centrifuged at $2000 \mathrm{~g}$ for $20 \mathrm{~min}$ at $4^{\circ} \mathrm{C}$ to remove unattached cells followed by a second round of centrifugation at $12,000 \mathrm{~g}\left(45 \mathrm{~min}\right.$ at $\left.4^{\circ} \mathrm{C}\right)$ to remove cell debris and large vesicles. The supernatant was then collected and passed through a 0.2 $\mu \mathrm{m}$ filter and ultracentrifuged at $110,000 \mathrm{~g}$ for $2 \mathrm{~h}$ at $4^{\circ} \mathrm{C}$ to pellet exosomes (Beckman Coulter Opitima L-90 K, SW32 Rotor). The pellet was washed with PBS to remove any possible co-precipitated protein complexes, and with a final round of centrifugation at $110,000 \mathrm{~g}$ for $2 \mathrm{~h}$ at $4^{\circ} \mathrm{C}$, the pellet was recovered and stored in $\mathrm{PBS}$ at $-80^{\circ} \mathrm{C}$.

\section{Exosome characterization}

The size distribution of exosomes was assessed using dynamic light scattering on a Zetasizer Nano ZS (Malvern Instruments, Ltd). Exosomes were characterized by western blot analysis. Cellular samples were lysed using RIPA buffer enriched with a cocktail of protease inhibitors (cOmplete, Mini, EDTA-free Protease Inhibitor Cocktail, Merck) at a concentration of $20 \mu \mathrm{L}$ per million of cells. Exosomal and cellular samples were denatured by boiling at $95^{\circ} \mathrm{C}$ for $7 \mathrm{~min}$ in $1 \times$ loading buffer (in nonreducing conditions for $\mathrm{CD} 9, \mathrm{CD} 63$ and $\mathrm{C} 81$, and in the presence of $\beta$-mercaptoethanol for cytochrome C, ANXA2 and AGO2). Equal amounts $(20 \mu \mathrm{g})$ of the protein lysates were electrophoresed on a $12 \%$ SDS-polyacrylamide gel and transferred to a polyvinylidene fluoride membrane using a wet transfer system. Using standard technique, the membranes were incubated with anti-CD9 (SC20048, Santa Cruz), anti-CD63 (106228D, Invitrogen), anti-CD81(10630D, Invitrogen), anti-Cytochrome C (556433, BD Pharmigen), anti-ANXA2 (D11G2, Cell Signaling), and anti-AGO2 (C34C6, Cell Signaling) antibodies. The blots were then incubated with the correspondent secondary antibodies and exposed to films.

\section{RNA extraction and RNA-seq library preparation}

For the cellular library preparation, $4 \times 10^{6}$ HUVECs were trypsinized and pelleted, and RNA was extracted using miRNeasy (Qiagen) following the manufacturer's instructions. Exosomes were purified from $20 \times 10^{6}$ HUVECs and the RNA was extracted using miRNeasy (Quiagen) with one modification: Five volumes of TRIzol were added to the exosomes; the volume of chloroform and ethanol were adjusted accordingly. RNA concentration was determined by Nanodrop (ThermoFisher) for cellular samples and with the Quant-it Ribogreen RNA assay kit (R11490, ThermoFisher) for exosomal RNA. To assess the quality of the samples, $2 \mu \mathrm{L}$ of RNA was analyzed using the RNA pico Agilent Bioanalyzer. Two biological replicates were prepared per condition. Small RNA libraries were generated using the TruSeq Small RNA Library Prep Kit (IRS-2000012, Illumina) for cellular and exosomal samples using $1 \mu \mathrm{g}$ and $15 \mathrm{ng}$ of RNA, respectively. The libraries were purified using a $6 \%$ Novex TBW polyacrylamide gel (EC6265BOX, Invitrogen) and the sequences ranging in size from 145 to $160 \mathrm{nt}$ were selected. For long RNAs, we used the TruSeq RNA Library Prep Kit (RS-1222001, Illumina) with a rRNA depletion step using RiboZero (MRZH116, Illumina) and starting with $1 \mu \mathrm{g}$ of cellular and 250 ng of exosomal RNA. In both cases, libraries were prepared following the manufacturer's instructions. Libraries were then analyzed on an Agilent Bioanalyzer DNA 1000 and quantified by qPCR using the Kapa kit (Kapa Biosystems). Sequencing was performed using an Illumina HiSeq 2000 (75-pb single-end reads) generating 40 million reads per long RNA libraries and 25 million reads for small RNA libraries.

\section{Analysis of RNA-seq data}

All the raw sequence files underwent a quality control analysis using FastQC (version 0.11.5). Remaining adaptor sequences of small RNA libraries were removed using Trimmomatic (Bolger et al. 2014) with the following parameters: seed mismatches 2, palindrome clip threshold 30, and simple clip threshold 12. Reads shorter than 16-nt post-trimming were discarded. Total RNA libraries were automatically trimmed during the demultiplexing by the core facility. For the identification of reads mapping against coding sequences, STAR (Dobin et al. 2013) was run with libraries prepared for total RNA. The mapper was used as default in quantification mode against the human genome and annotation (GRCh38) (Aken et al. 2017); a table of reads per gene was obtained for each sample with the results of the alignment. Total (long) RNA libraries were used to identify the number of sequences mapping against noncoding genes too. The reads were mapped against the ncRNA genome available from Ensembl (Pignatelli et al. 2016) using Bowtie2 (Langmead and Salzberg 2012). The mapping was performed in "local" mode and all valid alignments were reported. The number of reads per gene detected was counted using an in-house script. The Small RNA libraries were mapped against the miRNOME (Kozomara and Griffiths-Jones 2014), for the detection of microRNAs and against the noncoding genome (Pignatelli et al. 2016) for the remaining small RNAs classes. In both cases, the mapping was performed by Bowtie 2 using the mode "end-to-end" to ensure no clipping of the sequences. Only the best microRNA mapping to the reads was considered, while for noncoding RNA multiple mapping was allowed. For circularRNA detection, total RNA libraries were mapped against the GRCh38 genome using BWA (MEM mode) and known and potential circRNA candidates were detected using CIRI (Gao et al. 2015). A glossary of all the RNA species considered in this study can be found in Supplemental Table S1. The count of reads per gene was assessed using an in-house script and the heterogeneity of all replicates was assessed using a PCA table (Supplemental Fig. S1). All scripts are available upon request. A summary of the mapping strategy is available in Figure 1.

\section{RNA size and species distribution}

The size and abundance profile and the RNA class distribution analysis were performed using a series of in-house scripts (available upon request) counting the number of reads after trimming for every specific size or type of RNA in small RNA libraries. The relative abundances of noncoding RNA classes per fragment size in the small RNA libraries were measured after normalizing the data by library size and total number of reads mapping against each one of the RNA subclasses per (small) RNA library. 


\section{Relative abundance of RNA subclasses per compartment}

In order to study the proportion of RNA classes per compartment in short and long RNA libraries, the sequenced libraries were mapped against the full genome (GCRh38) allowing multiple mapping (some noncoding RNAs often fall within the coordinates of longer coding or noncoding RNAs). Then, the number of reads for each replicate and RNA class was normalized per library size. The number of different genes found for each RNA type was then normalized by the total number of genes detected in each replicate and represented in a percentage of all identified genes.

\section{Localization of RNA classes and analysis of differential expression}

In order to study which genes were significantly more represented in each compartment, we classified the genes identified only in cells, only in exosomes, or both in cells and exosomes with at least two reads per gene in all replicates. The number of genes found in common or only in cells or exosomes was then normalized by the total number of genes known per RNA class (extracted from the same genome annotation used during the library mapping). Differential expression analysis was performed in the raw data representing the total number of reads mapping to each gene found in both compartments using EdgeR (Robinson et al. 2010; McCarthy et al. 2012) after the samples were processed by the scaling normalization method (Robinson and Oshlack 2010). The statistical significance of the results was studied after correcting the $P$-values using the false discovery rate (FDR) method.

\section{Polarity of RNA fragments in mRNA genes}

To study if the mRNA fragments found in cells or in exosomes derived in the same regions of the gene ( $5^{\prime}$ and $3^{\prime}$ UTRs and coding sequence), a new annotation was constructed with the coordinates for the beginning and end of each one of the regions. Then, the genes with reads mapping against all regions were classified and processed with the scaling normalization method (Robinson and Oshlack 2010). The ratio between normalized reads in exosomes/normalized reads in cells was assessed for each one of the regions.

\section{Motif search and consensus sequence creation}

HOMER (Heinz et al. 2010) was the software used to find and identify any possible repetitive motifs. Genes were separated into the following categories: present only in cells or only in exosomes, present in both compartments (at least two reads per replicate) and significantly more or less present in exosomes (corrected $P$-value $<0.05$ ). The whole gene sequences of the identified RNAs were considered for the motif search. For each type of RNA, a background file with all the sequences detected in the study in the same RNA class was used to compare and perform the statistical analysis. Only statistically significant motifs not marked under "possible false positive" were considered. Significantly enriched motifs found in our study were manually compared to the sequences involved in the export of RNA molecules by hnRNPA2B1(GGAG) (Villarroya-Beltri et al. 2013), SYNCRIP (GGCUG) (Santangelo et al. 2016), and
YB1/NSUN2 (ACCAGCCU, CAGUGAGC, and UAAUCCCA) (Kossinova et al. 2017).

\section{DATA DEPOSITION}

Data files are accessible via GEO accession number GSE103831.

\section{SUPPLEMENTAL MATERIAL}

Supplemental material is available for this article.

\section{ACKNOWLEDGMENTS}

We thank the technology platforms support staff at the GIGA Research Center. This study was supported by the University of Liège (ULg), the Fonds National de la Recherche Scientifique (FNRS), Télévie, and the fonds Léon Frédéricq.

Received October 4, 2017; accepted December 21, 2017.

\section{REFERENCES}

Ahadi A, Brennan S, Kennedy PJ, Hutvagner G, Tran N. 2016. Long non-coding RNAs harboring miRNA seed regions are enriched in prostate cancer exosomes. Sci Rep 6: 24922.

Aken BL, Achuthan P, Akanni W, Amode MR, Bernsdorff F, Bhai J, Billis K, Carvalho-Silva D, Cummins C, Clapham P, et al. 2017. Ensembl 2017. Nucleic Acids Res 45: D635-D642.

Batagov AO, Kurochkin IV. 2013. Exosomes secreted by human cells transport largely mRNA fragments that are enriched in the $3^{\prime}$-untranslated regions. Biol Direct 8: 12.

Berrondo C, Flax J, Kucherov V, Siebert A, Osinski T, Rosenberg A, Fucile C, Richheimer S, Beckham CJ. 2016. Expression of the long non-coding RNA HOTAIR correlates with disease progression in bladder cancer and is contained in bladder cancer patient urinary exosomes. PLoS One 11: e0147236.

Beuck C, Williamson JR, Wüthrich K, Serrano P. 2016. The acidic domain is a unique structural feature of the splicing factor SYNCRIP. Protein Sci 25: 1545-1550.

Bolger AM, Lohse M, Usadel B. 2014. Trimmomatic: a flexible trimmer for Illumina sequence data. Bioinformatics 30: 2114-2120.

Cambier L, de Couto G, Ibrahim A, Echavez AK, Valle J, Liu W, Kreke M, Smith RR, Marbán L, Marbán E. 2017. Y RNA fragment in extracellular vesicles confers cardioprotection via modulation of IL-10 expression and secretion. EMBO Mol Med 9: 337-352.

Chakrabortty SK, Prakash A, Nechooshtan G, Hearn S, Gingeras TR. 2015. Extracellular vesicle-mediated transfer of processed and functional RNY5 RNA. RNA 21: 1966-1979.

Challagundla KB, Wise PM, Neviani P, Chava H, Murtadha M, Xu T, Kennedy R, Ivan C, Zhang X, Vannini I, et al. 2015. Exosome-mediated transfer of microRNAs within the tumor microenvironment and neuroblastoma resistance to chemotherapy. J Natl Cancer Inst 107: djv135.

Chen M, Xu R, Ji H, Greening DW, Rai A, Izumikawa K, Ishikawa H, Takahashi N, Simpson RJ. 2016. Transcriptome and long noncoding RNA sequencing of three extracellular vesicle subtypes released from the human colon cancer LIM1863 cell line. Sci Rep 6: 38397.

Choi KS, Mizutani A, Lai MMC. 2004. SYNCRIP, a member of the heterogeneous nuclear ribonucleoprotein family, is involved in mouse hepatitis virus RNA synthesis. J Virol 78: 13153-13162.

Crescitelli R, Lässer C, Szabó TG, Kittel A, Eldh M, Dianzani I, Buzás EI, Lötvall J. 2013. Distinct RNA profiles in subpopulations of extracellular vesicles: apoptotic bodies, microvesicles and exosomes. $J$ Extracell Vesicles 2: 20677. 
Dobin A, Davis CA, Schlesinger F, Drenkow J, Zaleski C, Jha S, Batut P, Chaisson M, Gingeras TR. 2013. STAR: ultrafast universal RNA-seq aligner. Bioinformatics 29: 15-21.

Duning K, Buck F, Barnekow A, Kremerskothen J. 2008. SYNCRIP, a component of dendritically localized mRNPs, binds to the translation regulator BC200 RNA. J Neurochem 105: 351-359.

Eliseeva IA, Kim ER, Guryanov SG, Ovchinnikov LP, Lyabin DN. 2011. Y-box-binding protein 1 (YB-1) and its functions. Biochemistry 76: 1402-1433.

Enderle D, Spiel A, Coticchia CM, Berghoff E, Mueller R, Schlumpberger M, Sprenger-Haussels M, Shaffer JM, Lader E, Skog J, et al. 2015. Characterization of RNA from exosomes and other extracellular vesicles isolated by a novel spin column-based method. PLoS One 10: e0136133.

Farris AD, O'Brien CA, Harley JB. 1995. Y3 is the most conserved small RNA component of Ro ribonucleoprotein complexes in vertebrate species. Gene 154: 193-198.

Friand V, David G, Zimmermann P. 2015. Syntenin and syndecan in the biogenesis of exosomes. Biol Cell 107: 331-341.

Fritz JV, Heintz-Buschart A, Ghosal A, Wampach L, Etheridge A, Galas D, Wilmes P. 2016. Sources and functions of extracellular small RNAs in human circulation. Annu Rev Nutr 36: 301-336.

Gao Y, Wang J, Zhao F. 2015. CIRI: an efficient and unbiased algorithm for de novo circular RNA identification. Genome Biol 16: 4.

Gezer U, Özgür E, Cetinkaya M, Işin M, Dalay N. 2014. Long non-coding RNAs with low expression levels in cells are enriched in secreted exosomes. Cell Biol Int 38: 1076-1079.

Guo T, Kong J, Liu Y, Li Z, Xia J, Zhang Y, Zhao S, Li F, Li J, Gu C. 2017. Transcriptional activation of NANOG by YBX1 promotes lung cancer stem-like properties and metastasis. Biochem Biophys Res Commun 487: 153-159.

Hannafon BN, Ding WQ. 2013. Intercellular communication by exosome-derived microRNAs in cancer. Int J Mol Sci 14: 14240-14269.

Heinz S, Benner C, Spann N, Bertolino E, Lin YC, Laslo P, Cheng JX, Murre C, Singh H, Glass CK. 2010. Simple combinations of lineage-determining transcription factors prime cis-regulatory elements required for macrophage and B cell identities. Mol Cell 38: 576-589.

Hewson C, Capraro D, Burdach J, Whitaker N, Morris KV. 2016. Extracellular vesicle associated long non-coding RNAs functionally enhance cell viability. Non-Coding RNA Res 1: 3-11.

Işin M, Uysaler E, Özgür E, Köseoğlu H, Şanlı Ö, Yücel ÖB, Gezer U, Dalay N. 2015. Exosomal lncRNA-p21 levels may help to distinguish prostate cancer from benign disease. Front Genet 6: 168.

Jenjaroenpun P, Kremenska Y, Nair VM, Kremenskoy M, Joseph B, Kurochkin IV. 2013. Characterization of RNA in exosomes secreted by human breast cancer cell lines using next-generation sequencing. PeerJ 1: e201.

Ji R, Zhang B, Zhang X, Xue J, Yuan X, Yan Y, Wang M, Zhu W, Qian H, $\mathrm{Xu}$ W. 2015. Exosomes derived from human mesenchymal stem cells confer drug resistance in gastric cancer. Cell Cycle 14: 2473-2483.

Joyce DP, Kerin MJ, Dwyer RM. 2016. Exosome-encapsulated microRNAs as circulating biomarkers for breast cancer. Int $J$ Cancer 139: 1443-1448.

Jung K, Wu F, Wang P, Ye X, Abdulkarim BS, Lai R. 2014. YB-1 regulates Sox2 to coordinately sustain stemness and tumorigenic properties in a phenotypically distinct subset of breast cancer cells. BMC Cancer 14: 328.

Kaudewitz D, Skroblin P, Bender LH, Barwari T, Willeit P, Pechlaner R, Sunderland NP, Willeit K, Morton AC, Armstrong PC, et al. 2016. Association of microRNAs and YRNAs with platelet function. Circ Res 118: 420-432.

Keerthikumar S, Chisanga D, Ariyaratne D, Al Saffar H, Anand S, Zhao K, Samuel M, Pathan M, Jois M, Chilamkurti N, et al. 2016. ExoCarta: a web-based compendium of exosomal cargo. J Mol Biol 428: 688-692.

Kosaka N, Yoshioka Y, Hagiwara K, Tominaga N, Ochiya T. 2013. Functional analysis of exosomal microRNA in cell-cell communication research. Methods Mol Biol 1024: 1-10.
Kossinova OA, Gopanenko AV, Tamkovich SN, Krasheninina OA, Tupikin AE, Kiseleva E, Yanshina DD, Malygin AA, Ven'yaminova AG, Kabilov MR, et al. 2017. Cytosolic YB-1 and NSUN2 are the only proteins recognizing specific motifs present in mRNAs enriched in exosomes. Biochim Biophys Acta 1865: 664-673.

Kozomara A, Griffiths-Jones S. 2014. miRBase: annotating high confidence microRNAs using deep sequencing data. Nucleic Acids Res 42: D68-D73

Kuchler L, Giegerich AK, Sha LK, Knape T, Wong MSK, Schröder K, Brandes RP, Heide H, Wittig I, Brüne B, et al. 2014. SYNCRIP-dependent Nox2 mRNA destabilization impairs ROS formation in M2-polarized macrophages. Antioxid Redox Signal 21: 2483-2497.

Lang HL, Hu GW, Chen Y, Liu Y, Tu W, Lu YM, Wu L, Xu GH. 2017. Glioma cells promote angiogenesis through the release of exosomes containing long non-coding RNA POU3F3. Eur Rev Med Pharmacol Sci 21: 959-972.

Langmead B, Salzberg SL. 2012. Fast gapped-read alignment with Bowtie 2. Nat Methods 9: 357-359.

Lázaro-Ibáñez E, Lunavat TR, Jang SC, Escobedo-Lucea C, Oliver-De La Cruz J, Siljander P, Lötvall J, Yliperttula M. 2017. Distinct prostate cancer-related mRNA cargo in extracellular vesicle subsets from prostate cell lines. BMC Cancer 17: 92.

Lerner MR, Boyle JA, Hardin JA, Steitz JA. 1981. Two novel classes of small ribonucleoproteins detected by antibodies associated with lupus erythematosus. Science 211: 400-402.

Lévesque K, Halvorsen M, Abrahamyan L, Chatel-Chaix L, Poupon V, Gordon H, DesGroseillers L, Gatignol A, Mouland AJ. 2006. Trafficking of HIV-1 RNA is mediated by heterogeneous nuclear ribonucleoprotein A2 expression and impacts on viral assembly. Traffic 7: 1177-1193.

Li L, Li C, Wang S, Wang Z, Jiang J, Wang W, Li X, Chen J, Liu K, Li C, et al. 2016. Exosomes derived from hypoxic oral squamous cell carcinoma cells deliver miR-21 to normoxic cells to elicit a prometastatic phenotype. Cancer Res 76: 1770-1780.

Li Q, Shao Y, Zhang X, Zheng T, Miao M, Qin L, Wang B, Ye G, Xiao B, Guo J. 2015. Plasma long noncoding RNA protected by exosomes as a potential stable biomarker for gastric cancer. Tumour Biol 36: 2007-2012.

Lim JP, Shyamasundar S, Gunaratne J, Scully OJ, Matsumoto K, Bay BH. 2017. YBX1 gene silencing inhibits migratory and invasive potential via CORO1C in breast cancer in vitro. BMC Cancer 17: 201.

Liu HM, Aizaki H, Choi KS, Machida K, Ou JJH, Lai MMC. 2009. SYNCRIP (synaptotagmin-binding, cytoplasmic RNA-interacting protein) is a host factor involved in hepatitis $C$ virus RNA replication. Virology 386: 249-256.

Liu T, Zhang X, Gao S, Jing F, Yang Y, Du L, Zheng G, Li P, Li C, Wang C. 2016. Exosomal long noncoding RNA CRNDE-h as a novel serum-based biomarker for diagnosis and prognosis of colorectal cancer. Oncotarget 7: 85551-85563.

Lobb RJ, van Amerongen R, Wiegmans A, Ham S, Larsen JE, Möller A. 2017. Exosomes derived from mesenchymal non-small cell lung cancer cells promote chemoresistance. Int J Cancer 141: 614-620.

Lötvall J, Hill AF, Hochberg F, Buzás EI, Di Vizio D, Gardiner C, Gho YS, Kurochkin IV, Mathivanan S, Quesenberry P, et al. 2014. Minimal experimental requirements for definition of extracellular vesicles and their functions: a position statement from the International Society for Extracellular Vesicles. J Extracell Vesicles 3: 26913.

Lv J, Huang Z, Liu H, Liu H, Cui W, Li B, He H, Guo J, Liu Q, Zhang Y, et al. 2014. Identification and characterization of long intergenic non-coding RNAs related to mouse liver development. Mol Genet Genomics 289: 1225-1235.

Lyabin DN, Eliseeva IA, Ovchinnikov LP. 2014. YB-1 protein: functions and regulation. Wiley Interdiscip Rev RNA 5: 95-110.

Mateescu B, Kowal EJK, van Balkom BWM, Bartel S, Bhattacharyya SN, Buzás EI, Buck AH, de Candia P, Chow FWN, Das S, et al. 2017. Obstacles and opportunities in the functional analysis of 
extracellular vesicle RNA-an ISEV position paper. J Extracell Vesicles 6: 1286095.

Mathivanan S, Ji H, Simpson RJ. 2010. Exosomes: extracellular organelles important in intercellular communication. J Proteomics 73: 1907-1920.

McCarthy DJ, Chen Y, Smyth GK. 2012. Differential expression analysis of multifactor RNA-Seq experiments with respect to biological variation. Nucleic Acids Res 40: 4288-4297.

Milane L, Singh A, Mattheolabakis G, Suresh M, Amiji MM. 2015. Exosome mediated communication within the tumor microenvironment. J Control Release 219: 278-294.

Miranda KC, Bond DT, Levin JZ, Adiconis X, Sivachenko A, Russ C, Brown D, Nusbaum C, Russo LM. 2014. Massively parallel sequencing of human urinary exosome/microvesicle RNA reveals a predominance of non-coding RNA. PLoS One 9: e96094.

Momen-Heravi F, Saha B, Kodys K, Catalano D, Satishchandran A, Szabo G. 2015. Increased number of circulating exosomes and their microRNA cargos are potential novel biomarkers in alcoholic hepatitis. J Transl Med 13: 261.

Moser JJ, Eystathioy T, Chan EKL, Fritzler MJ. 2007. Markers of mRNA stabilization and degradation, and RNAi within astrocytoma GW bodies. J Neurosci Res 85: 3619-3631.

Munro TP, Magee RJ, Kidd GJ, Carson JH, Barbarese E, Smith LM, Smith R. 1999. Mutational analysis of a heterogeneous nuclear ribonucleoprotein A2 response element for RNA trafficking. J Biol Chem 274: $34389-34395$.

Okoye IS, Coomes SM, Pelly VS, Czieso S, Papayannopoulos V, Tolmachova T, Seabra MC, Wilson MS. 2014. MicroRNA-containing T-regulatory-cell-derived exosomes suppress pathogenic T helper 1 cells. Immunity 41: 89-103.

Øverbye A, Skotland T, Koehler CJ, Thiede B, Seierstad T, Berge V, Sandvig K, Llorente A. 2015. Identification of prostate cancer biomarkers in urinary exosomes. Oncotarget 6: 30357-30376.

Pan L, Liang W, Fu M, Huang ZH, Li X, Zhang W, Zhang P, Qian H, Jiang PC, Xu WR, et al. 2017. Exosomes-mediated transfer of long noncoding RNA ZFAS1 promotes gastric cancer progression. $J$ Cancer Res Clin Oncol 143: 991-1004.

Peake PW, Pianta TJ, Succar L, Fernando M, Pugh DJ, McNamara K, Endre ZH. 2014. A comparison of the ability of levels of urinary biomarker proteins and exosomal mRNA to predict outcomes after renal transplantation. PLoS One 9: e98644.

Pignatelli M, Vilella AJ, Muffato M, Gordon L, White S, Flicek P, Herrero J. 2016. ncRNA orthologies in the vertebrate lineage. Database 2016: bav127.

Provencio M, Rodríguez M, Cantos B, Sabín P, Quero C, GarcíaArroyo FR, Rueda A, Maximiano C, Rodríguez-Abreu D, Sánchez A, et al. 2017. mRNA in exosomas as a liquid biopsy in non-Hodgkin lymphoma: a multicentric study by the Spanish Lymphoma Oncology Group. Oncotarget 8: 50949-50957.

Qu L, Ding J, Chen C, Wu ZJ, Liu B, Gao Y, Chen W, Liu F, Sun W, Li XF, et al. 2016. Exosome-transmitted lncARSR promotes sunitinib resistance in renal cancer by acting as a competing endogenous RNA. Cancer Cell 29: 653-668.

Quek C, Bellingham SA, Jung CH, Scicluna BJ, Shambrook MC, Sharples RA, Cheng L, Hill AF. 2017. Defining the purity of exosomes required for diagnostic profiling of small RNA suitable for biomarker discovery. RNA Biol 14: 245-258.

Repetto E, Lichtenstein L, Hizir Z, Tekaya N, Benahmed M, Ruidavets JB, Zaragosi LE, Perret B, Bouchareychas L, Genoux A, et al. 2015. RNY-derived small RNAs as a signature of coronary artery disease. BMC Med 13: 259.

Robinson MD, McCarthy DJ, Smyth GK. 2010. edgeR: a Bioconductor package for differential expression analysis of digital gene expression data. Bioinformatics 26: 139-140.

Robinson MD, Oshlack A. 2010. A scaling normalization method for differential expression analysis of RNA-seq data. Genome Biol 11: R25.

Sánchez CA, Andahur EI, Valenzuela R, Castellón EA, Fullá JA, Ramos CG, Triviño JC. 2016. Exosomes from bulk and stem cells from human prostate cancer have a differential microRNA content that contributes cooperatively over local and pre-metastatic niche. Oncotarget 7: 3993-4008.

Santangelo L, Giurato G, Cicchini C, Montaldo C, Mancone C, Tarallo R, Battistelli C, Alonzi T, Weisz A, Tripodi M. 2016. The RNA-binding protein SYNCRIP is a component of the hepatocyte exosomal machinery controlling microRNA sorting. Cell Rep 17: 799-808.

Schwarzenbach H. 2015. The clinical relevance of circulating, exosomal miRNAs as biomarkers for cancer. Expert Rev Mol Diagn 15: $1159-1169$.

Shurtleff MJ, Temoche-Diaz MM, Karfilis KV, Ri S, Schekman R. 2016. Y-box protein 1 is required to sort microRNAs into exosomes in cells and in a cell-free reaction. eLife 5: e19276.

Simons M, Raposo G. 2009. Exosomes-vesicular carriers for intercellular communication. Curr Opin Cell Biol 21: 575-581.

Skogberg G, Gudmundsdottir J, van der Post S, Sandström K, Bruhn S, Benson M, Mincheva-Nilsson L, Baranov V, Telemo E, Ekwall O. 2013. Characterization of human thymic exosomes. PLoS ONE 8: e67554.

Solé C, Cortés-Hernández J, Felip ML, Vidal M, Ordi-Ros J. 2015. miR$29 \mathrm{c}$ in urinary exosomes as predictor of early renal fibrosis in lupus nephritis. Nephrol Dial Transplant 30: 1488-1496.

Suzuki H, Matsuoka M. 2017. hnRNPA1 autoregulates its own mRNA expression to remain non-cytotoxic. Mol Cell Biochem 427: 123-131.

Tsochandaridis M, Nasca L, Toga C, Levy-Mozziconacci A. 2015. Circulating microRNAs as clinical biomarkers in the predictions of pregnancy complications. BioMed Res Int 2015: 294954.

Umezu T, Tadokoro H, Azuma K, Yoshizawa S, Ohyashiki K, Ohyashiki JH. 2014. Exosomal miR-135b shed from hypoxic multiple myeloma cells enhances angiogenesis by targeting factor-inhibiting HIF-1. Blood 124: 3748-3757.

van Balkom BWM, Eisele AS, Pegtel DM, Bervoets S, Verhaar MC. 2015. Quantitative and qualitative analysis of small RNAs in human endothelial cells and exosomes provides insights into localized RNA processing, degradation and sorting. J Extracell Vesicles 4: 26760.

Villarroya-Beltri C, Gutiérrez-Vázquez C, Sánchez-Cabo F, PérezHernández D, Vázquez J, Martin-Cofreces N, MartinezHerrera DJ, Pascual-Montano A, Mittelbrunn M, SánchezMadrid F. 2013. Sumoylated hnRNPA2B1 controls the sorting of miRNAs into exosomes through binding to specific motifs. Nat Commun 4: 2980.

Wang J, Zhou Y, Lu J, Sun Y, Xiao H, Liu M, Tian L. 2014. Combined detection of serum exosomal miR-21 and HOTAIR as diagnostic and prognostic biomarkers for laryngeal squamous cell carcinoma. Med Oncol 31: 148.

Wu SL, Fu X, Huang J, Jia TT, Zong FY, Mu SR, Zhu H, Yan Y, Qiu S, $\mathrm{Wu}$ Q, et al. 2015. Genome-wide analysis of YB-1-RNA interactions reveals a novel role of YB-1 in miRNA processing in glioblastoma multiforme. Nucleic Acids Res 43: 8516-8528.

Xu JF, Wang Y, Zhang SJ, Chen Y, Gu HF, Dou XF, Xia B, Bi Q, Fan SW. 2017. Exosomes containing differential expression of microRNA and mRNA in osteosarcoma that can predict response to chemotherapy. Oncotarget 5: 75968-75978.

Yoon C, Kim J, Park G, Kim S, Kim D, Hur DY, Kim B, Kim YS. 2016. Delivery of miR-155 to retinal pigment epithelial cells mediated by Burkitt's lymphoma exosomes. Tumour Biol 37: 313-321.

Zhang J, Kong L, Guo S, Bu M, Guo Q, Xiong Y, Zhu N, Qiu C, Yan X, Chen Q, et al. 2017. hnRNPs and ELAVL1 cooperate with uORFs to inhibit protein translation. Nucleic Acids Res 45: 2849-2864.

Zhao X, Liu Y, Yu S. 2017. Long noncoding RNA AWPPH promotes hepatocellular carcinoma progression through YBX1 and serves as a prognostic biomarker. Biochim Biophys Acta 1863: 1805-1816.

Zhou J, Gong G, Tan H, Dai F, Zhu X, Chen Y, Wang J, Liu Y, Chen P, $\mathrm{Wu} \mathrm{X}$, et al. 2015. Urinary microRNA-30a-5p is a potential biomarker for ovarian serous adenocarcinoma. Oncol Rep 33: 2915-2923. 

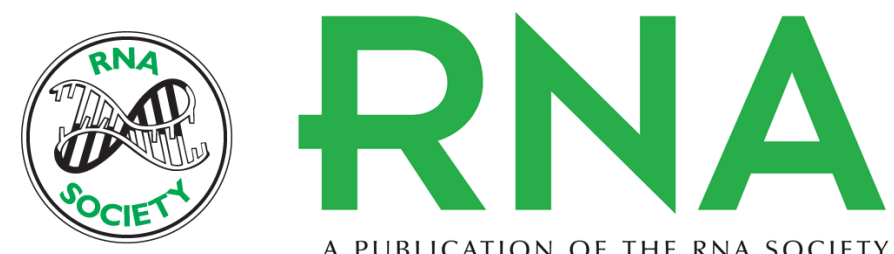

A PUBLICATION OF THE RNA SOCIETY

\section{Exploring the RNA landscape of endothelial exosomes}

Jennifer Pérez-Boza, Michelle Lion and Ingrid Struman

RNA 2018 24: 423-435 originally published online December 27, 2017

Access the most recent version at doi:10.1261/rna.064352.117

Supplemental Material

References

Creative Commons License

Email Alerting Service
http://rnajournal.cshlp.org/content/suppl/2017/12/27/rna.064352.117.DC1

This article cites 88 articles, 8 of which can be accessed free at: http://rnajournal.cshlp.org/content/24/3/423.full.html\#ref-list-1

This article is distributed exclusively by the RNA Society for the first 12 months after the full-issue publication date (see http://rnajournal.cshlp.org/site/misc/terms.xhtml). After 12 months, it is available under a Creative Commons License (Attribution-NonCommercial 4.0 International), as described at http://creativecommons.org/licenses/by-nc/4.0/.

Receive free email alerts when new articles cite this article - sign up in the box at the top right corner of the article or click here. 